\title{
Determinants and trends in perinatal human immunodeficiency virus type 1 (HIV-1) transmission in the metropolitan area of Belo Horizonte, Brazil: 1998 - 2005
}

\author{
Fabiana Maria Kakehasi, Jorge A Pinto $/{ }^{1 /}$, Roberta Maia de Castro Romanelli, \\ Mariângela Carneiro $/{ }^{2}$, Carolina Silva Cardoso, Maria do Carmo Teatini Tavares $/{ }^{3}$, \\ Victor Hugo Melo/ ${ }^{4}$, Regina Amélia Lopes Pessoa de Aguiar ${ }^{4}$
}

\begin{abstract}
Grupo de Aids Materno-Infantil 'Departamento de Pediatria ${ }^{4}$ Departamento de Ginecologia e Obstetrícia, Faculdade de Medicina, ${ }^{2}$ Epidemiologia de Doenças Infecciosas e Parasitárias, Departamento de Parasitologia, Instituto de Ciências Biológicas Universidade Federal de Minas Gerais, Av. Alfredo Balena 190, s/ 161, 30130-100 Belo Horizonte, MG, Brasil ${ }^{3}$ Centro de Treinamento e Referência em Doenças Infecciosas e Parasitárias Orestes Diniz, Secretaria de Saúde da Prefeitura Municipal de Belo Horizonte, MG Brasil
\end{abstract}

Significant decrease in human immunodeficiency virus type 1 (HIV-1) vertical transmission has been observed worldwide in centers where interventions such as antiretroviral therapy (ART), elective cesarean section, and avoidance of breastfeeding have been implemented. This prospective cohort study aimed to assess the determinants of and the temporal trends in HIV-1 vertical transmission in the metropolitan area of Belo Horizonte, Brazil from January 1998 to December 2005. The rate of HIV-1 vertical transmission decreased from 20\% in 1998 to 3\% in 2005. This decline was associated with increased use of more complex ART regimens during pregnancy. Multivariate analysis restricted to clinical variables demonstrated that non ART, neonatal respiratory distress/sepsis and breastfeeding were independently associated with HIV-1 vertical transmission. When laboratory parameters were included in the model, high maternal viral load and non maternal ART were associated with HIV-1 vertical transmission. The results from this study confirm the impact of ART in the reduction of HIV-1 vertical transmission and indicate the need for improvement in the care and monitoring of mother and infant pairs affected by HIV-1.

Key words: HIV-1 - vertical transmission - pregnant women - antiretroviral therapy

By the end of 2006, it was estimated that almost 39.5 (CI95\%: 34.1-47.1) million adults and children were infected with the human immunodeficiency virus (HIV-1) worldwide, with 1.7 million (CI95\%: 1.3-2.5) HIV-1positive individuals living in Latin America (UNAIDS 2007). The vertical transmission of HIV-1 is the major route for HIV-1 acquisition in children, and 13,012 cases of pediatric acquired immunodeficiency syndrome (AIDS) cases have been reported in Brazil (MS 2007a). In the absence of interventions, the reported HIV-1 vertical transmission rate varies from 15 to $25 \%$ in Europe and the USA and extending to $40 \%$ in under-developed countries (WGMCT 1995). In Brazil, initial studies demonstrated a transmission rate of $16 \%$ (CI 95\%: 13-20) (Tess et al. 1998), but a significant decrease has been observed in recent years; a nation-wide study reported a transmission rate of $7.1 \%$ in 2001, but centers in Rio de Janeiro and São Paulo have described lower rates $(3.57 \%$ between 1996 to 2001 and $2.4 \%$ in 2002, for each city respectively) (João et al. 2003, Matida et al. 2005, Succi 2007). Brazilian data reflect the progress achieved in the reduction of HIV-1 vertical transmission reported worldwide in centers where maternal antiretroviral therapy (ART) and breast milk replacement are available

\footnotetext{
Financial Support: $\mathrm{CNPq}$

+Corresponding author: jpinto@medicina.ufmg.br

Received: 30 January 2008

Accepted: 5 June 2008
}

(Dorenbaum et al. 2002, Wade et al. 2004, Magder et al. 2005, Newell et al. 2007).

The Pediatric AIDS Clinical Trials Group Protocol 076, a multicenter study published in 1994 (Connor et al. 1994) demonstrated a decrease of $67.5 \%$ in the HIV-1 vertical transmission rate when zidovudine (ZDV) was offered prophylactically to HIV-1 pregnant women and to their newborns. Following this landmark study, different ART regimens have demonstrated variable impact in the reduction of HIV-1 vertical transmission rates (Dabis et al. 1999, Guay et al. 1999, Shaffer et al. 1999, Wiktor et al. 1999, PST 2002, Lallemant et al. 2004, Read et al. 2007). In addition to ART, other interventions have contributed to the reduction of HIV-1 vertical transmission, such as elective cesarean section (C-section) (IPHIVG 1999, EMDC 1999), vaginal cleaning during the intrapartum period (Taha et al. 1997), vitamin A supplementation (Semba 1997), and avoidance of breastfeeding (Nduati et al. 2001, RoUsseau et al. 2004).

The objective of this prospective study was to evaluate the determinants associated with HIV-1 transmission and to describe the temporal trends in HIV-1 vertical transmission rates in the metropolitan area of Belo Horizonte (BH), Brazil, from January 1998 to December 2005.

\section{PATIENTS, MATERIALS AND METHODS}

Population - This prospective observational study was carried out at the main referral center for HIV-1/ AIDS care and treatment in BH (Centro de Referência em Doenças Infecciosas e Parasitárias Orestes Diniz UFMG/PBH). Eligible cases included HIV-1 infected 
pregnant women and/or mothers and their exposed babies who were admitted before three months of age to the outpatient clinic. The participants were enrolled from January 1998 to December 2005.

Data collection - Clinical and laboratory data were collected using standardized forms. Maternal data included HIV-1 route of acquisition, date of diagnosis, pregnancy and delivery history, ART during pregnancy, and disease classification (revised by CDC 1992). Results from maternal $\mathrm{CD} 4^{+}$lymphocyte count and viral load closest to delivery were also collected for analysis. Results from tests performed between three months prior to to three months post delivery date were considered. Infants were evaluated monthly for the first six months of life and every three months thereafter until definition of HIV-1 status was determined. CD4 $4^{+}$lymphocyte count and plasma viral load were performed in infected infants every three months.

Definitions - Mode of delivery was categorized as elective $\mathrm{C}$-section or other. ART regimens were described as ZDV monotherapy, dual nucleoside reverse transcriptase inhibitor therapy (NRTI; ZDV plus another NRTI), highly active ART therapy (HAART; 2 NRTIs plus 1 protease inhibitor or 1 non-NNRTI), or no therapy at any stage of gestation. Duration of ruptured membranes was considered prolonged if it occurred prior to $4 \mathrm{~h}$ of delivery.

Infants were classified as low birth weight if they weighed less than $2.500 \mathrm{~g}$ and classified as premature if they were born at less than 37 weeks of gestational age assessed by Capurro et al. (1978) method. HIV-1 infection was defined in infants who presented: (i) a plasma viral load greater than 10,000 copies per $\mathrm{ml}$ in two samples collected after four weeks of life; (ii) any class $\mathrm{C}$ diagnosis according to CDC (1994) pediatric HIV-1/AIDS case definition; or (iii) a persistent positive HIV-1 antibody exam (enzyme-linked immunoassay and western blot) after 18 months of age. Uninfected infants were defined as those who presented with two negative plasma viral load exams after four weeks of life or those who seroreverted (a negative serologic test performed after 12 months of age). All mothers were counseled to not breastfeed.

Statistical analysis - The relationships between maternal factors and HIV-1 status of the infants were first analyzed by univariate analysis using the chi-square test, Fisher's exact test, chi square for trend test, MannWhitney test, estimative of odds ratio (OR), and $95 \%$ CI. Following univariate analysis, the independent contribution from risk factors was assessed using stepwise logistic regression. The initial model included all variables with p-values less than 0.25 or those variables known to have biological plausibility for perinatal HIV-1 transmission. New models were built using a backward process with statistical significance determined by the likelihood ratio test (Hosmer \& Hjort 2002). Interactions between variables selected for the final multivariate model were also considered if they remained significantly associated with the transmission risk. Statistical analyses were performed using SPSS version 12.0 (SPSS Inc. Chicago IL USA).
The study was approved by the Ethical Comitee from Universidade Federal de Minas Gerais (ETIC 008/97) and all participants provided writen informed consent.

\section{RESULTS}

During the period from January 1998 to December 2005, 939 mother-infant pairs were evaluated. Analyses were performed with 900 pairs; data from 39 (4.2\%) pairs were either lost to follow-up or reported no infection status at time of analysis. HIV-1 vertical transmission occurred in 56 infants, with an overall rate of transmission of $6.2 \%$ (95\% CI: 4.8-8.1). A significant decrease in transmission was observed throughout the study period (Fig. 1) $(\mathrm{p}<0.05)$. The relative reduction in HIV-1 vertical transmission rate from 1998 to 2005 was $85 \%$.

Maternal characteristics - No maternal demographic characteristics were associated with HIV-1 vertical transmission: Overall, $46.6 \%$ of mothers had mixed ethnic origin ("mulata"), $63.8 \%$ had a stable marital status, and $62.8 \%$ had less than eight years of formal education. Transmitting and non-transmitting mothers had similar median ages (26.0 and 27.9 years, respectively; $p=$ 0.30 ). Illicit drug use was not associated with transmission (OR 1.0, 95\% CI: 0.4-2.5). Information on route of HIV-1 acquisition was available for $93.1 \%$ of the women and sexual contact with HIV-1-positive partner was reported by $96.9 \%$ of the women. The majority of mothers were asymptomatic or had mild manifestations (CDC 1992 , class $\mathrm{A}=60 \%) . \mathrm{CD}^{+}$lymphocyte counts and plasma viral load were available for $49.4 \%$ and $55.4 \%$, respectively, of the HIV-1-infected mothers (Table I). Median time of these blood tests from delivery (pre to post) was 6.4 weeks for $\mathrm{CD}^{+}$count (interquartile range: IQR25\%-75\%: 2.0-6.4) and six weeks for viral load assessment (IQR25\%-75\%: 2.1-13.7). Transmitting mothers were significantly more immunossupressed and demonstrated higher plasma viremia than non-transmitting

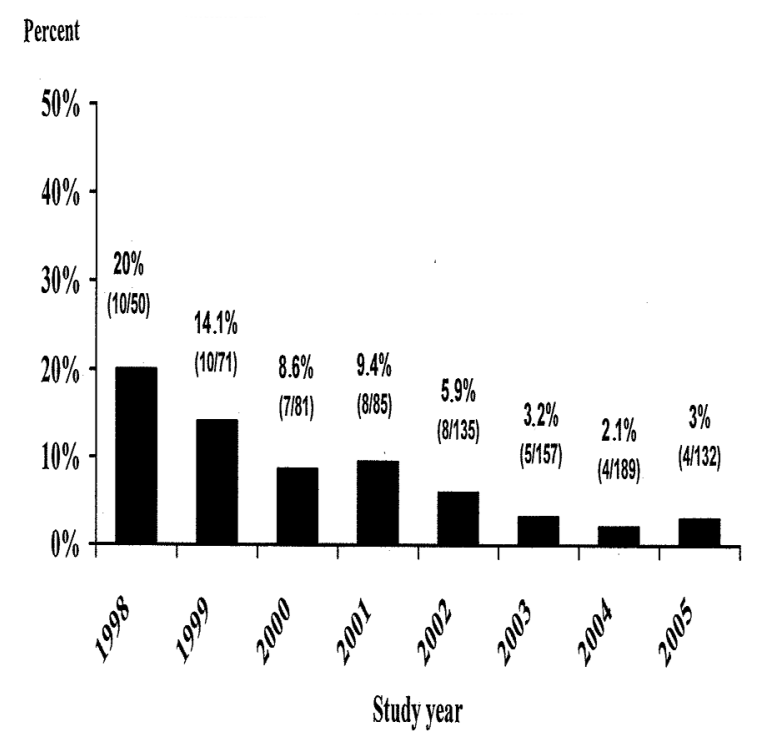

Fig. 1: HIV vertical transmission rate among HIV-infected women per study year, from 1998 to 2005 . 
TABLE I

Characteristics of women and infants in the study population, according to HIV vertical transmission $(\mathrm{n}=900)$

\begin{tabular}{|c|c|c|c|}
\hline Characteristics & HIV Transmission: Yes $(\mathrm{n}=56)$ & HIV Transmission: No $(\mathrm{n}=844)$ & Statistic \\
\hline & & Maternal data & \\
\hline Median age (years) & 26.0 & 27.9 & $0.30^{a}$ \\
\hline \multicolumn{4}{|l|}{ Antiretroviral Regimen ${ }^{b}$} \\
\hline None $(\%)$ & $34 / 48(70.8 \%)$ & $100 / 764(13.1 \%)$ & $8.0(3.2-20.7)$ \\
\hline ZDV monotherapy (\%) & $7 / 48(14.6 \%)$ & $165 / 764(21.6 \%)$ & $6.1(1.4-29.9)$ \\
\hline Dual therapy $(\%)$ & $4 / 48(8.3 \%)$ & $70 / 764(9.2 \%)$ & $8.2(1.5-47.1)$ \\
\hline HAART $(\%)$ & $3 / 48(6.3 \%)$ & $429 / 764(56.1 \%)$ & $1^{\mathrm{c}}$ \\
\hline Prolonged rupture of membranes $(\%)^{b}$ & $4 / 43(9.3 \%)$ & $56 / 774(7.2 \%)$ & $1.32^{c}(0.4-4.0)$ \\
\hline \multicolumn{4}{|l|}{ Mode of delivery $(\%)^{b}$} \\
\hline Elective C-section & $21 / 56(37.5 \%)$ & $534 / 842(63.4 \%)$ & $1^{\mathrm{c}}$ \\
\hline Emergence C-section & $02 / 56(3.6 \%)$ & $53 / 842(6.3 \%)$ & $0.98(0.15-4.34)$ \\
\hline Vaginal delivery & $33 / 56(58.9 \%)$ & $255 / 842(30.3 \%)$ & $3.33(1.82-5.88)$ \\
\hline Median CD4 count (cells $\left./ \mathrm{mm}^{3}\right)$ & 330 & 465 & $0.01^{a}$ \\
\hline (IQR 25\%-75\%) & $(221-457)$ & $(312-639)$ & \\
\hline Median Plasma Viral Load (log) & 4.30 & 2.66 & $0.00^{a}$ \\
\hline (IQR 25\%-75\%) & $(3.2-4.9)$ & $(0.0-3.7)$ & \\
\hline \multirow[t]{2}{*}{ Viral load $>1,000$ copies/ml $(\%)$} & $23 / 25(92 \%)$ & $239 / 509(47 \%)$ & $13.0(2.9-80.6)$ \\
\hline & & Infant data & \\
\hline Birth Weight (grams) & 2,890 & 2,910 & $0.25^{a}$ \\
\hline (IQR 25\%-75\%) & $(2,875-3,443)$ & $(2,600-3,420)$ & \\
\hline Low birth weight $(\%)^{b}$ & $14 / 55(25.5 \%)$ & $171 / 834(20.5 \%)$ & $1.3^{c}(0.7-2.6)$ \\
\hline Prematurity $(\%)^{b}$ & $11 / 55(20 \%)$ & $95 / 815(11.7 \%)$ & $1.9^{c}(0.9-3.9)$ \\
\hline Neonatal Morbidity $(\%)^{b}$ & $30 / 56(53.6 \%)$ & $203 / 844(24.1 \%)$ & $3.6^{c}(2.0-6.3)$ \\
\hline Breastfeeding $(\%)^{b}$ & $19 / 56(33.9 \%)$ & $36 / 844(4.3 \%)$ & $11.53^{c}(7.8-23.1)$ \\
\hline Median CD4 count $\left(\right.$ cells $\left./ \mathrm{mm}^{3}\right)$ & 1,792 & 2,554 & $0.00^{a}$ \\
\hline (IQR 25\%-75\%) & $(1,040-2,325)$ & $(1,858-3,339)$ & \\
\hline
\end{tabular}

$a$ : Mann Whitney Test; $b$ : Qui-square; $c$ : Odds ratio (CI 95\%); IQR: interquartile range.

mothers. Maternal viral load greater than 1,000 copies $/ \mathrm{ml}$ was significantly associated with vertical transmission (OR 13.0, 95\%CI: 2.9-80.6); however, we were not able to establish a plasma viral load threshold that predicted mother-to-child transmission.

Obstetric history - Neither rupture of membranes prior to $4 \mathrm{~h}$ of delivery, complications during pregnancy, nor maternal death were associated with an increased risk of HIV-1 vertical transmission. Rates for mode of delivery varied throughout the study period: Elective Csection rates rose until 2001 and then declined; rates for vaginal deliveries increased since 2001 (Fig. 2). Rates of non-elective $\mathrm{C}$-section deliveries remained stable during the study years, accounting for less than $7 \%$ of deliveries. Vaginal deliveries were associated with increased risk of transmission (OR 3.33, 95\% CI: 1.82-5.88).

In this cohort, ART during pregnancy has shown to increase from $66.7 \%$ in 1998 to $89.9 \%$ in 2005 ( $\mathrm{p}=\mathrm{NS}$ ). In the first three years of this study, ZDV monotherapy and dual therapy (2 NRTI drugs, including ZDV) were the most common ART regimens used by pregnant women (Fig. 3). HAART increased from $11.1 \%$ in 1998 to $76.1 \%$ in 2005 (chi-square for trend $=134.67, \mathrm{p}<0.05$ ) and it was inversely correlated with HIV-1 vertical transmission rates.
Infant follow-up - Mean birth weights for infected and uninfected infants was 2,890 $\mathrm{g}$ and 2,910 g, respectively $(\mathrm{p}=0.25)$. Numbers of low birth weight (infected: $25.5 \%$ vs. uninfected: $20.5 \%, p=0.39$ ) and premature (infected: $20 \%$ vs. uninfected: $11.7 \%, \mathrm{p}=0.07$ ) infants

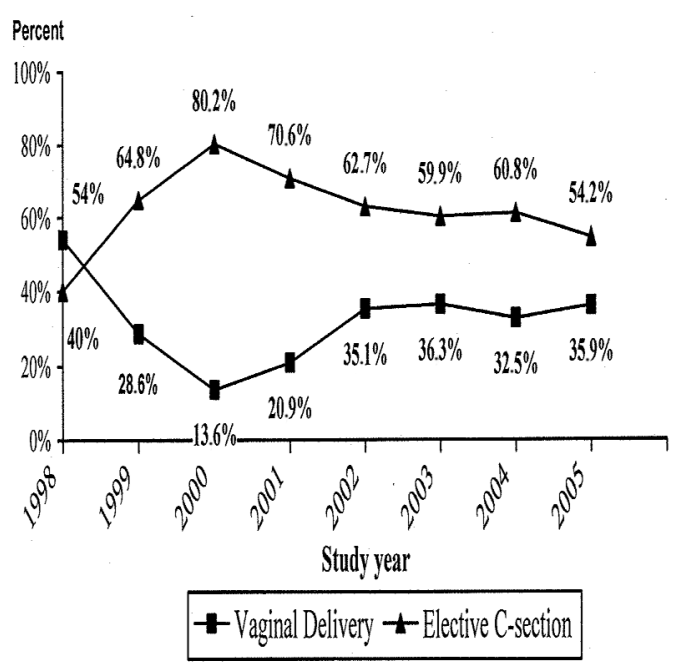

Fig. 2: rate of elective $\mathrm{C}$-section and vaginal deliveries among HIV infected pregnant women, from 1998 to 2005. 


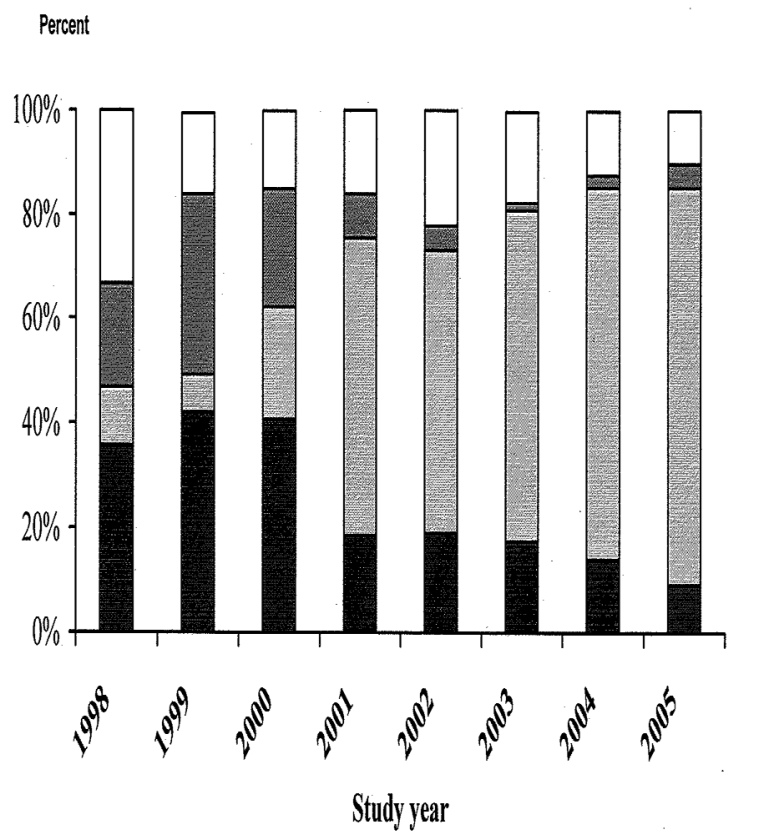

ZZDV Monotherapy GHAART TOthers (double ARV) DNone drug used

Fig. 3: antiretroviral schema used among HIV-infected pregnant women, from 1998 to 2005.

occurred equally between infected and uninfected. Breastfeeding was significantly higher among infected compared to uninfected infants (infected: $4.3 \%$ vs. uninfected: $33.9 \%$ ) and represented an important risk factor for HIV-1 vertical transmission $(\mathrm{OR}=11.5,95 \% \mathrm{CI}$ : $7.8-23.1, \mathrm{p}<0.05)$ as shown in Table II. Neonatal morbidities due to sepsis and respiratory discomfort were associated with HIV-1 vertical transmission (OR 3.6, 95\%CI: 2.0-6.3). Although still in the normal range, infected presented decreased $\mathrm{CD}^{+}$lymphocyte counts in the first trimester of life when compared with uninfected (median values: infected: 1,792 cells $/ \mathrm{ml}$ vs. uninfected: $2.555, \mathrm{p}<0.05$, median age of collection $=1.9$ months).

Multivariate analysis - Two models were analyzed in this cohort: one model included only clinical data (Model 1) and a second model included both clinical and laboratory data $\left(\mathrm{CD}^{+}\right.$lymphocyte count and viral load; Model 2). Among the available 900 mother-infant pairs, the clinical-only model included $748(83.1 \%)$ pairs and the clinical and laboratory model comprised 339 (37.7\%) pairs. The initial step in both models included the logistic modeling of all variables that demonstrated known biological plausibility for HIV-1 vertical transmission or demonstrated statistical importance in the initial univariate analysis (Table II). Model 1 included delivery type (elective $\mathrm{C}$-section vs other), timing of amniotic membrane rupture ( $<$ or $>4 \mathrm{~h}$ prior to delivery), ART use (ZDV, ZDV + NRTI, HAART, or no therapy), prematurity $(<37$ weeks gestational age), birth weight $(\mathrm{g})$, neonatal disease and breastfeeding as variables. Model 2 included all clinical variables listed above and added absolute $\mathrm{CD}^{+}$lymphocyte count and plasma viral load
TABLE II

Multivariate analyses of factors associated with HIV vertical transmission performed in two models

\begin{tabular}{lccc}
\hline Models and variables & Adjusted OR & $95 \%$ CI & p-value \\
\hline Model 1: clinical data $^{a}$ & & & \\
Neonatal diseases & 2.3 & $1.1-4.9$ & 0.026 \\
Breastfeeding & 3.1 & $1.2-8.0$ & 0.023 \\
Absence of maternal ART use & 9.0 & $4.1-20.0$ & 0.000 \\
Model 2: clinical and laboratory data & & & \\
Maternal viral load by log & 2.3 & $1.2-4.4$ & 0.008 \\
Absence of maternal ART use & 7.3 & $1.5-34.5$ & 0.013 \\
\hline
\end{tabular}

$a$ : variables included in a full model were time of membrane rupture, prematurity, birth weight, breastfeeding, maternal antiretroviral use, neonatal diseases and C-section $(\mathrm{n}=748)$; $b$ : variables included in a full model were membrane rupture, prematurity, birth weight, breastfeeding, neonatal diseases, antiretroviral use, C-section, maternal viral load by log and maternal absolute CD4 count $(n=339)$.

in log scale (Table II). Absence of maternal ART was the major independent risk factor associated with an increased risk in both models. Despite that prematurity was not a significant independent risk factor in the clinical model, neonatal disease was associated with HIV-1 vertical transmission. Multiplicative interactions between breast feeding or prematurity and neonatal disease were not statistically significant $(\mathrm{p}=0.08$ and $\mathrm{p}=0.918$, respectively). In Model 2, higher maternal viral load was associated with a two-fold increased risk of HIV-1 vertical transmission. There was no interaction between maternal viral load and ART during pregnancy $(\mathrm{p}=0.49)$

\section{DISCUSSION}

The rate of HIV-1 vertical transmission declined from $20 \%$ to $3 \%$ during the seven-year period (1998-2005) of this prospective observational study carried out at a HIV-1/AIDS referral center in BH: The relative reduction was $85 \%$. This decline is similar to what has been reported in other studies both in-country and internationally (João et al. 2003, Wade et al. 2004, Matida et al. 2005, Succi 2007), demonstrating the effectiveness of strategies aimed at reducing mother to child transmission. Results from a multicenter observational study conducted in Latin America and Caribbean countries that included 770 mother-infant exposed to different ART regimens (Read et al. 2007) also demonstrated a low $(0.91 \%, 95 \%$ CI: 0.37 - 1.86) HIV-1 mother to child transmission rate. The National AIDS Brazilian Program (NAP) has been providing routine HIV-1 testing for all pregnant women during prenatal care and for all HIV-1 exposed babies at birth. In addition NAP has been providing infant formula, ART drugs, and laboratory monitoring universally and free of charge. The NAP strategy focuses on all steps to block HIV-1 vertical transmission (MS 2007b).

The conclusions drawn from our study could have been affected by selection bias or our studied cohort might not be representative of all HIV-1-infected pregnant women from metropolitan BH. However, this po- 
tential bias is attenuated by the fact that we are the only referral center for the care of HIV-1 exposed and infected children in the area.

In this observational study there were no differences in the transmission rates between mothers who had prolonged rupture of membranes ( $>4 \mathrm{~h}$ prior to delivery) or any reported complication during pregnancy. In a metaanalysis conducted by the IPHIVG (2001) the probability of HIV-1 vertical transmission rate increased from $8 \%$ (for rupture $2 \mathrm{~h}$ prior to delivery) to $32 \%$ (for rupture $24 \mathrm{~h}$ prior to delivery) among HIV-1-infected women. Other studies have also described associations between premature labor, intrapartum transmission, and timing of rupture of membranes among HIV-1-infected women (Magder et al. 2005). However, the contribution of complex ART regimens was not addressed in this study, in which the majority of women were exposed to ZDV monotherapy or less complex regimens.

The $\mathrm{C}$-section pattern described in this current study is similar to the increasing proportion of $\mathrm{C}$-section rates among HIV-1-infected women performed in the US. Dominguez et al. (2003) observed that the proportion of deliveries conducted by C-section increased from $24 \%$ before June 1998 to $58 \%$ after June 1998. Similarly, an increase in C-section rates was detected by the ECS (2005) from 1985 to 2004. It was recommended that all HIV-1infected pregnant women be offered elective $\mathrm{C}$-sections to reduce HIV-1 vertical transmission, including women receiving ART (ECS 2005). A recent publication comparing characteristics of HIV-1-infected pregnant women from Europe and the USA demonstrated a greater elective C-section delivery rate in Europe (61\% vs $22 \%$, Europe vs. USA, respectively), but an earlier initiation of ART and HAART in the USA (Newell et al. 2007). It is likely that the release of the results from EMDC study (1999) was an important determinant for the increment in C-section rates, especially in Brazil and European countries. It is important to emphasize that the HIV-1 vertical transmission rates continued to decline, even when the elective C-section rates reached a plateau around 2002. This trend was probably associated with the increased use of HAART regimens as depicted in Fig. 3.

The importance of maternal viremia was confirmed in the second model of the multivariate analysis. This factor was associated with an increased risk of HIV-1 vertical transmission (OR 2.3, 95\% CI: 1.2-4.4) consistent with results from international studies including the women infant transmission study (WITS) (OR 2.4, 95\% CI: 1.69-2.34), an African study (OR 2.66, 95\% CI: 1.95-3.63), and the NICHD International Site Development Initiative study (OR3.3, 95\% CI: 2.0-5.4) (Cooper et al. 2002, Taha et al. 2004, Read et al. 2007). However, the quality of prenatal care remains a key issue: The large numbers of mothers without assessment of $\mathrm{CD}^{+}$ lymphocyte count and viral load are an indirect marker of missed opportunities in prenatal care. Additionally, the extended interval between laboratory assessment and delivery time is a limitation that may potentially compromise our findings and conclusions. Despite the significant difference between mean viral load in mother to child transmission and non- mother to child transmission, a threshold for predicting mother to child transmission was not established, similar to other studies (Mayaux et al. 1997, Garcia et al. 1999, ECS 2005, Read et al 2007).

The maternal use of combined ART regimens has increased significantly throughout the study period. This finding is consistent to what has been reported in a large American cohort of HIV-1 infected women (Tuomala et al. 2002) that demonstrated a significant increase in HAART use with and without protease inhibitor from the early 90 s to 1998 . In the WITS study, HIV-1 vertical transmission rate was $20 \%$ for women not receiving prenatal ART 10.4\% for those receiving ZDV monotherapy, $3.8 \%$ for multi-ART, and $1.2 \%$ for HAART (Cooper et al. 2002). Unfortunately, our study did not measure the duration of therapy during pregnancy or assess the suppression of viral replication. The benefit of ART was confirmed and this was independently associated with a reduction in the HIV-1 vertical transmission in both scenarios described in the multivariate analyses as is historically demonstrated in maternal-to-child transmission.

In our study, low birth weight and prematurity were observed equally among infected and exposed/uninfected. However, other studies have reported low birth weight (LBW) and prematurity to be associated with mother to child transmission, and a possible explanation for the discrepancy could be the higher frequency of LBW and prematurity described in other populations (Nogueira et al. 2001, João et al. 2003, Magder et al. 2005, Szyld et al. 2006). However, neonatal diseases such as respiratory distress syndrome, sepsis, and neonatal jaundice were associated with HIV-1 vertical transmission indicating that others factors are associated with the newborn infection. In addition, the administration of ART to mothers and ZDV to infants that is associated with elective $\mathrm{C}$-section could also have contributed to the prevention of mother to child transmission of HIV-1 in most of our preterm and LBW infants. Also, the current study did not demonstrate a demographic difference among infected and non-infected newborns; it was not possible to demonstrate the timing of HIV-1 infection, whether intra or peripartum (Bryson et al. 1992, Kalish et al. 1997). A significant issue to be addressed is the high frequency of breastfeeding in a country where formula is available. This statistic could reflect a subgroup of HIV-1 infected women that had not been diagnosed during pregnancy or at labor. Unfortunately, time of maternal diagnosis was not addressed in our study. The opportunity to advise against breastfeeding was missed in this subpopulation and thus, a number of HIV-1 transmissions were not avoided. Neonatal disease can predict if an exposed baby is HIV-1-infected, but prematurity does not influence this factor. A lower $\mathrm{CD} 4^{+}$lymphocyte count was present in HIV-1 infected children. However this finding is normal for children of this age, and thus additional studies must be done to establish the value of this measure for predicting risk of infection and disease.

This current study reports a decrease in HIV-1 vertical transmission rates for metropolitan $\mathrm{BH}$ and also reports the impact of ART on the reduction of infection rates in this population. The real scenario in impover- 
ished communities is as is expressed in Model 1, where only clinical data are available to predict the risk of HIV-1 vertical transmission. It has clearly been observed that two interventions must be implemented: avoidance of breastfeeding, and maternal/neonatal ART. The effectiveness of high quality, multidisciplinary prenatal care can improve the maternal-infant follow-up and outcomes.

\section{REFERENCES}

Bryson YJ, Luzuriaga K, Sullivan JL, Wara DW 1992. Proposed definitions for in utero versus intrapartum transmission of HIV-1. N Engl J Med 327: 1246-1247.

Capurro H, Korichzky S, Fonseca O, Caldeiro-Barcia R 1978. A simplified method for diagnosis of gestational age in the newborn enfant. J Pediatr 93:120-122.

CDC - Centers for Disease Control and Prevention 1992.Revised classification system for HIV infection and expanded surveillance case definition for AIDS among adolescents and adults. MMWR Recomm Rep 41: 1-19.

CDC - Centers for Disease Control and Prevention 1994. Revised classification system for human immunodeficiency virus (HIV) infection in children under 13 years of age. MMWR Morb Mortal Wkly Rep 43: 1-10.

Connor EM, Sperling RS, Gelber R, Kiselev P, Scott G, O’Sullivan MJ, VanDyke R, Bey M, Shearer W, Jacobson RL, Jimenez R, O’Neill E, Bazin B, Delfraissy JF, Culnane M, Coombs R, Elkins M, Moye J, Stratton P, Balsley J, for The Pediatric AIDS Clinical Trials Group Protocol 076 Study Group 1994. Reduction of maternal-infant transmission of human immunodeficiency virus type 1 with zidovudine treatment. Pediatric AIDS Clinical Trials Group Protocol 076 Study Group. N Engl J Med 331: 1173-1180.

Cooper ER, Charurat M, Mofenson L, Hanson IC, Pitt J, Diaz C, Hayani K, Handelsman E, Smeriglio V, Hof R, Blattner W, Women and Infnats Transmission Study Group 2002. Combination antiretroviral strategies for the treatment of pregnant HIV-1infected women and prevention of perinatal HIV-1 transmission. J Acquir Immune Defic Syndr 29: 484-494.

Dabis F, Msellati P, Meda N, Welfens-Ekra C, You B, Manigart O, Leroy V, Simonon A, Cartoux M, Combe P, Ouangré A, Ramon R, Ky-Zerbo O, Montcho C, Salamon R, Rouzioux C, Van de Perre P, Mandelbrot L 1999. Six-month efficacy, tolerance, and acceptability of a short regimen of oral zidovudine to reduce vertical transmission of HIV in breastfed children in Côte d'Ivoire and Burkina Faso: a double-blind placebo-controlled multicentre trial. DITRAME Study Group. Diminution de la Transmission Mère-Enfant. Lancet 353: 786-792.

Dominguez KL, Lindegren ML, D’Almada PJ, Peters VB, Frederick T, Rakusan TA, Ortiz IR, Hsu HW, Melville SK, Sadek R, Fowler MG, Pediatric Spedtrum of HIV Disease Consortium 2003. Increasing trend of cesarean deliveries in HIV-infected women in the United States from 1994 to 2000. J Acquir Immune Defic Syndr 33: 232-238.

Dorenbaum A, Cunningham CK, Gelber RD, Culnane M, Mofenson L, Britto P, Rekacewicz C, Newell ML, Delfraissy JF, Cunningham-Shrader B, Mirochnick M, Sulivan JL, International PACTG316 Team 2002. Two-dose intrapartum/newborn nevirapine and standard antiretroviral therapy to reduce perinatal HIV transmission: a randomized trial. JAMA 288: 189-198.

ECS - European Collaborative Study 2005. Mother-to-child transmission of HIV infection in the era of highly active antiretroviral therapy. Clin Infect Dis 40: 458-465.
EMDC - The European Mode of Delivery Collaboration 1999. Elective caesarean-section versus vaginal delivery in prevention of vertical HIV-1 transmission: a randomised clinical trial. The European Mode of Delivery Collaboration. Lancet 353: 1035-1039.

Garcia PM, Kalish LA, Pitt J, Minkoff H, Quinn TC, Burhett SK, Kornegav J, Jackson B, Moye J, Hanson C, Zorilla C, Lew JF 1999. Maternal levels of plasma human immunodeficiency virus type 1 RNA and the risk of perinatal transmission. Women and Infants Transmission Study Group. N Engl J Med 341: 394-402.

Guay LA, Musoke P, Fleming T, Bagenda D, Allen M, Nakabiito C, Sherman J, Bakaki P, Ducar C, Deseyve M, Emel L, Mirochnick M, Fowler MG, Mofenson L, Miotti P, Dransfield K, Bray D, Mmiro F, Jackson JB 1999. Intrapartum and neonatal single-dose nevirapine compared with zidovudine for prevention of motherto-child transmission of HIV-1 in Kampala, Uganda: HIVNET 012 randomised trial. Lancet 354: 795-802.

Hosmer DW, Hjort NL 2002. Goodness-of-fit processes for logistic regression: simulation results. Stat Med 21: 2723-2738.

IPHIVG - The International Perinatal HIV Group 1999. The mode of delivery and the risk of vertical transmission of human immunodeficiency virus type 1- a meta-analysis of 15 prospective cohort studies. The International Perinatal HIV Group. $N$ Engl $J$ Med 340: 977-987.

João EC, Cruz ML, Menezes JA, Matos HJ, Calvet GA, d'Ippolito MM, Salgado LT, Silva SS, Bazin GR, Braga RC 2003. Vertical transmission of HIV in Rio de Janeiro, Brazil. AIDS 17: 1853-1855.

Kalish LA, Pitt J, Lew J, LandesmanS, Diaz C, Hershow R, Hollinger FB, Pagano M, Smerigli V, Moye J 1997. Defining the time of fetal or perinatal acquisition of human immunodeficiency virus type 1 infection on the basis of age at first positive culture. Women and Infants Transmission Study (WITS). J Infect Dis 175: 712-715.

Lallemant M, Jourdain G, Le Coeur S, Mary JY, Ngo-Giang-Houng N, Koetsawang S, Kanshana S, McIntosh K, Thaineua V, Perinatal HIV Prevention Trial Investigators 2004. Single-dose perinatal nevirapine plus standard zidovudine to prevent mother-to-child transmission of HIV-1 in Thailand. N Engl J Med 351: 217-228.

Magder LS, Mofenson L, Paul ME, Zorilla CD, Blattner WA, Tuomola RE, LaRussa P, Landesman S, Rich KC 2005. Risk factors for in utero and intrapartum transmission of HIV. J Acquir Immune Defic Syndr 38: 87-95.

Matida LH, da Silva MH, Tayra A, Succi RC, Gianna MC, Gonçalves A, de Carvalho HB, Hearst N 2005. Prevention of mother-tochild transmission of HIV in São Paulo State, Brazil: an update. AIDS 19 (Suppl 4): S37-41.

Mayaux MJ, Dussaix E, Isopet J, Rekacewicz C, Mandelbrot L, Ciraru-Vigneron N, Allemon MC, Chambrin V, Katlama C, Delfraissy JF, Puel J 1997. Maternal virus load during pregnancy and mother-to-child transmission of human immunodeficiency virus type 1: the French perinatal cohort studies. SEROGEST Cohort Group. J Infect Dis 175: 172-175.

MS - Ministério da Saúde 2007a. Programa Nacional de DST e AIDS, MS-PNDST/AIDS, Boletim Epidemiológico [serial on the Internet]; 4(1) [cited 2007 Jan]. Available from:http://www.aids.gov.br/ data/documents/storedDocuments/\%7BB8EF5DAF-23AE-4891AD36-1903553A3174\%7D/\%7B721527B6-FE7A-40DF-91C4098BE8C704E0\%7D/Boletim2007_internet090108.pdf.

MS - Ministério da Saúde 2007b. Recomendações para Profilaxia da Transmissão Vertical do HIV e Terapia Anti-Retroviral em Gestantes - 2006. Secretaria de Vigilância em Saúde [cited $2007 \mathrm{Jan}$ ]. Available from: http:// www.aids.gov.br/data/documents/storedDocuments/\%7BB8EF5DAF23AE-4891-AD36-1903553A3174\%7D/\%7B672FA510-A29641BC-9D63-D413775714BA\%7D/Consenso\%20gestantes $\% 20$ 2007\%20-\%20final.pdf. 
Nduati R, Richardson BA, John G, Mbori-Ngacha D, Mwatha A, Ndinya-Achola J, Bwayo J, Onyango FE, Kreiss J 2001. Effect of breastfeeding on mortality among HIV-1 infected women: a randomised trial. Lancet 357: 1651-1655.

Newell ML, Huang S, Fiore S, Thorne C, Mandelbrot L, Sullivan JL, Maupin R, Delke I, Watts DH, Gelber RD, Cunningham CK, PACTG 316 Study Team 2007. Characteristics and management of HIV-1-infected pregnant women enrolled in a randomised trial: differences between Europe and the USA. BMC Infect Dis 7: 60 .

Nogueira SA, Abreu T, Oliveira R, Araújo L, Costa T, Andrade M, Garcia MF, Rodrigues K, Mercadante R, Fernandes I, Sapia MC, Lambert JS 2001. Successful prevention of HIV transmission from mother to infant in Brazil using a multidisciplinary team approach. Braz J Infect Dis 5: 78-86.

PST - Petra Study Team 2002. Efficacy of three short-course regimens of zidovudine and lamivudine in preventing early and late transmission of HIV-1 from mother to child in Tanzania, South Africa, and Uganda (Petra study): a randomised, double-blind, placebo-controlled trial. Lancet 359: 1178-1186.

Read JS, Cahn P, Losso M, Pinto J, Joao E, Duarte G, Cardoso E, Freimanis-hance L, Stoszek SK; NISDI Perinatal Study Group 2007. Management of human immunodeficiency virus-infected pregnant women at Latin American and Caribbean sites. Obstet Gynecol 109: 1358-1367.

Rousseau CM, Nduati RW, Richardson BA, John-Stewart GC, MboriNgacha DA, Kreiss JK, Overbauh J 2004. Association of levels of HIV-1-infected breast milk cells and risk of mother-to-child transmission. J Infect Dis 190: 1880-1888.

Semba RL 1997 Overview of the potential role of vitamin A in mother-to-child transmission of HIV-1. Acta Paediatr 421 (Suppl.): 107-112.

Shaffer N, Chuachoowong R, Mock PA, Bhadrakom C, Siriwasin W, Young NL, Chotpitayasunondh T, Chearsdkul S, Roongpisuthipong A, Chinayon P, KaronJ, Mastro TD, Simonds RJ 1999. Shortcourse zidovudine for perinatal HIV-1 transmission in Bangkok, Thailand: a randomised controlled trial. Bangkok Collaborative Perinatal HIV Transmission Study Group. Lancet 353: 773-780.

Succi RCM 2007. Mother-to-child transmission of HIV in Brazil during the years 2000 and 2001: results of a multi-centric study. Cad Saúde Pública 23 (Suppl. 3): S379-S389.
Szyld EG, Warley EM, Freimanis L, Gonin R, Cahn PE, Calvet GA, Duarte G, Melo VH, Read JS, NISDI Periantal Study Group 2006. Maternal antiretroviral drugs during pregnancy and infant low birth weight and preterm birth. AIDS 20: 2345-2353.

Taha TE, Biggar RJ, Broadhead RL, Mtimavalve LA, Justesen AB, Liomba GN, Chiphanqwi JD, Miotti PG 1997. Effect of cleansing the birth canal with antiseptic solution on maternal and newborn morbidity and mortality in Malawi: clinical trial. BMJ 315: 216-219.

Taha TE, Kumwenda NI, Hoover DR, Fiscus SA, Kafulafula G, Nkhoma C, Nour S, Chen S, Liomba G, Miotti PG, Broadhead RL 2004. Nevirapine and zidovudine at birth to reduce perinatal transmission of HIV in an African setting: a randomized controlled trial. JAMA 292: 202-209.

Tess BH, Rodrigues LC, Newell ML, Dunn DT, Lago TD 1998. Infant feeding and risk of mother-to-child transmission of HIV-1 in São Paulo State, Brazil. São Paulo Collaborative Study for Vertical Transmission of HIV-1. J Acquir Immune Defic Syndr Hum Retrovirol 19: 189-194.

UNAIDS - Joint United Nations Programme on HIV/AIDS (UNAIDS) and World Health Organization 2007. AIDS epidemic update. [cited 2007 Jan]. Available from: http://www.unaids.org/en/ KnowledgeCentre/HIVData/EpiUpdate/EpiUpdArchive/2007/.

Tuomala RE, Shapiro DE, Mofenson LM, Bryson Y, Culnane M, Hughes MD, O'Sullivan MJ, Scott G, Stek AM, Wara D, Bulterys M 2002. Antiretroviral therapy during pregnancy and the risk of an adverse outcome. N Engl J Med. Jun 346: 1863-1870.

Wade NA, Zielinski MA, Butsashvili M, McNutt LA, Warren BL, Glaros R, Cheku B, Pulver W, Pass K, Fox K, Novello AC, Birkhead GS 2004. Decline in perinatal HIV transmission in New York State (1997-2000). J Acquir Immune Defic Syndr 36: 1075-1082.

Wiktor SZ, Ekpini E, Karon JM, Nkengasong J, Maurice C, Severin ST, Roels TH, Kouassi MK, Lackritz EM, Coulibaly IM, Greenberg AE 1999. Short-course oral zidovudine for prevention of mother-to-child transmission of HIV-1 in Abidjan, Côte d'Ivoire: a randomised trial. Lancet 353: 781-785.

WGMTCT - The Working Group on Mother-To-Child Transmission of HIV 1995. Rates of mother-to-child transmission of HIV-1 in Africa, America, and Europe: results from 13 perinatal studies. $J$ Acquir Immune Defic Syndr Hum Retrovirol 8: 506-510. 